\title{
"PACOTE DO VENENO": Poder do Agronegócio e Violações aos Direitos à Saúde, à Segurança Alimentar e ao Meio Ambiente
}

\author{
http://dx.doi.org/10.21527/2176-6622.2020.54.91-105
}

Recebido em: 7/5/2020

Modificações solicitadas em: 26/6/2020

Aceito em: 21/7/2020

\section{RESUMO}

\section{Lauren Caroline Rodrigues Zanuto} Graduação em Direito pela Pontifícia Universidade Católica de Campinas (2019). http://lattes.cnpq. br/9289039188094387. https://orcid.org/0000-0003-4728-1244. lauren_carol@hotmail.com

\section{Guilherme Perez Cabral}

Professor titular da Pontifícia Universidade Católica de Campinas (PUC-Campinas). Membro do corpo docente permanente do Programa de Pós-Graduação Stricto Sensu em Direito (PPGD). Membro do grupo de pesquisa "Direito num mundo globalizado" (CNPq/PUC Campinas). Doutor em Direito pela Universidade de São Paulo (2014). Mestre em Direito pela Universidade Metodista de Piracicaba (2008) e graduado em Direito pela PUC-Campinas (2003). Integra o Banco de Avaliadores do Sistema Nacional de Avaliação da Educação Superior Basis. http://lattes.cnpq.br/9267585007227859. https://orcid.org/0000-0003-4480-3641. gpcabral@gmail.com

O modelo de produção agrícola adotado no Brasil, com grande concentração de renda e de terras, além do cultivo de monoculturas voltado para a exportação, existente desde a colônia, foi ainda mais impulsionado no século 20 pela chamada Revolução Verde. A introdução de maquinários e o uso de agrotóxicos, desde então, somente se intensificou. Assim, neste artigo tratamos do "Pacote do Veneno" (Projeto de Lei no 6.299 de 2002 e apensados) e sua proposta de flexibilização da legislação hoje vigente no que diz respeito à regulamentação para uso e comercialização destes produtos. O objetivo foi verificar se há conflito de interesses entre o avanço e possível aprovação do projeto e a proteção aos direitos à saúde, à segurança alimentar e ao meio ambiente. À luz do arcabouço jurídico nacional e internacional, além da análise de conteúdo do projeto e da pesquisa bibliográfica, identificamos que, em última análise, as alterações legislativas servirão aos interesses daqueles que pretendem a manutenção do poderio econômico e político do agronegócio.

Palavras-chave: Agronegócio. Agrotóxicos. Saúde. Meio ambiente. Pacote do veneno.

\section{"POISON PACKAGE": THE POWER OF AGROBUSINESS AND VIOLATIONS} OF THE RIGHTS TO HEALTH, FOOD SAFETY AND THE ENVIRONMENT

\section{ABSTRACT}

The model of agricultural production adopted in Brazil, with a high concentration of income and land, and the cultivation of monocultures, focused on exports, existing since the colony, was further boosted in the 20th century by the so-called Green Revolution. The implantation of machinery and the use of pesticides, since then, have only intensified. In this article, therefore, we analyze the "Poison Package" ("Projeto de Lei no 6.299 de 2002" and attached) and its proposal to make the current legislation more flexible with regard to the regulations for the use of the marketing of these products. The purpose was to verify if there is a conflict of interest between the progress and possible approval of the project and the protection of the environment, health rights and food safety. Considering the national and international legal framework, in addition to the content analysis of the project and bibliographic research, we identified that, in the final analysis, the legislative changes will serve the interests of those who intend to maintain the economic and political power of agribusiness.

Keywords: Agrobusiness. Pesticides. Health. Environment. "Poison package".

\section{SUMÁRIO}

1 Introdução. 2 Um breve histórico do uso de agrotóxicos no Brasil e a interferência do capital na agricultura. 3 Direitos humanos à saúde, à segurança alimentar e ao meio ambiente e a regulação do uso de agrotóxicos no Brasil. 40 pacote do veneno e o debate no Congresso. 4.10 Projeto de Lei no 6.299/2002 e seus apensados. 4.2 O parecer favorável do então deputado Luiz Nishimori. 5 O pacote do veneno e o parecer da comissão especial: expediente para o crescimento econômico do agronegócio e violações aos direitos humanos. 6 Considerações finais. 7 Referências. 


\section{INTRODUÇÃO}

O Brasil é, desde 2008, o maior consumidor mundial de agrotóxicos, sendo sua maior concentração de uso nas grandes produções dos commodities pelo agronegócio, seguindo o modelo de produção que prioriza os bens para exportação. No ano de 2011, "as lavouras de soja, milho, algodão e cana-de-açúcar representam $80 \%$ do total das vendas do setor" (CARNEIRO et al., 2015, p. 49-50).

Atualmente, o registro e a comercialização destes produtos no país são regulamentados pela Lei 7.802/1989, documento normativo que confere alguma proteção e estabelece critérios para sua utilização, aprovado após intenso embate entre os que pretendiam maior liberalização para o uso dos agrotóxicos e os que defendiam a necessidade de uma legislação mais rigorosa (FOLGADO, 2016a).

O agronegócio é historicamente um dos grandes setores de concentração de renda no Brasil, sobretudo com as mudanças ocorridas na esteira da chamada "Revolução Verde", responsável pela mecanização da agricultura e pelo início da utilização em larga escala dos agrotóxicos (CARNEIRO et al., 2015). Aqui, "o termo agronegócio representa o atual modelo hegemônico de produção na agricultura, modelo que, por sua vez, é a continuidade da chamada revolução verde, o processo que representou o controle da agricultura pela indústria" (FOLGADO, 2016a, p. 259).

Essa escalada ocorreu com forte atuação do governo federal, citando-se, nesse sentido, o "Sistema Nacional de Crédito Rural", instituído em 1965 pela Lei n ${ }^{\circ}$ 4.829, de 5 de novembro de 1965, e o "Plano Nacional de Defensivos Agrícolas", criado no âmbito do II Plano Nacional de Desenvolvimento do ano de 1975. O primeiro condicionava a obtenção de crédito agrícola à compra de agrotóxicos, enquanto o segundo garantia suporte financeiro para a instalação de empresas de "insumos agrícolas" no país (LONDRES, 2011, p. 18).

Esse suporte governamental perdura até hoje. O Convênio ICMS 100/97, por exemplo, confere 60\% de redução da alíquota do ICMS para a circulação de todos os agrotóxicos, e foi prorrogado pelo Convênio ICMS $22 / 2020$, pelo menos, até $31 / 12 / 2020$, conforme informação disponível na página do Conselho Nacional de Política Fazendária.

O uso de agrotóxicos acarreta diversos perigos à saúde, ao meio ambiente e à alimentação adequada, principalmente. São produtos constituídos a partir de diversas sustâncias químicas, com efeitos que vão desde a alteração da saúde reprodutiva ao aumento do desenvolvimento de câncer em seres humanos, especialmente em trabalhadores rurais. Quanto ao meio ambiente, causam contaminação de comunidades de seres vivos que não são seu alvo e de águas superficiais e subterrâneas (PERES; MOREIRA; DUBOIS, 2003).

O apoio do Poder Público ao agronegócio e, nele, aos grandes proprietários, é muito presente, ainda, no Poder Legislativo federal. Materializa-se na chamada "Bancada Ruralista", ou Frente Parlamentar da Agropecuária, que, na 56a legislatura (período de 2019 a 2022), soma 225 deputados federais e 36 senadores $^{1}$.

O setor ruralista hoje garante sua hegemonia por intermédio da ação parlamentar desenvolvida por seus congressistas, em que a dominação e a exploração parecem ganhar o status inquestionável de Lei, e, ainda, pela cooptação dos meios de comunicação, que distorcem toda e qualquer ação de contestação das tradicionais estruturas fundiárias, e da violência armada, amparada na prerrogativa constitucional do direito à propriedade (SIMIONATTO; COSTA, 2012, p. 224).

Nesse cenário de favorecimento ao agronegócio e à utilização de agrotóxicos, foi apresentado, em 2002, o Projeto de Lei 6.299, de autoria do então senador federal Blairo Maggi, e a ele foram apensados outros 41 projetos.

Visando a alterar a hoje vigente Lei de Agrotóxicos, o chamado "Pacote do Veneno", caso aprovado, irá flexibilizar a regulamentação e possibilitar o aumento do uso de agrotóxicos sob o pretexto de que a legislação atual está defasada e impede o progresso do agronegócio. Nas palavras do deputado federal Luiz Nishimori (Partido da República), em seu parecer favorável à aprovação do Projeto, "passadas quase três décadas, o sistema de registro e de uso de pesticidas está esgotado" (BRASIL, 2018, p. 16).

\footnotetext{
FRENTE PARLAMENTAR DA AGROPECUÁRIA (Brasil). Composição. [2019-2022]. Disponível em: https://www.camara.leg.br/internet/ deputado/frenteDetalhe.asp?id=53910. Acesso em: 13 abr. 2019.
} 
Assim, neste artigo analisamos o Projeto de Lei, seus apensos, bem como o parecer favorável à sua aprovação, apresentado em 2018 pelo deputado federal Luiz Nishimori. O objetivo da pesquisa foi aferir as possíveis violações aos direitos humanos que as alterações trazidas poderão acarretar, principalmente no que diz respeito ao meio ambiente, à segurança alimentar e à saúde. Buscamos verificar, finalmente, quem serão os beneficiados pela eventual aprovação do Pacote do Veneno.

O estudo foi feito à luz dos Tratados Internacionais de Direitos Humanos dos quais o Brasil é signatário - especificamente o Pacto Internacional dos Direitos Econômicos, Sociais e Culturais, a Convenção no 155 da Organização Internacional do Trabalho e as Convenções de Roterdã e Estocolmo, além do arcabouço legislativo nacional, sobretudo da Constituição Federal, que estabelece o direito ao meio ambiente ecologicamente equilibrado (Artigo 225), à saúde e à alimentação adequada (artigo 6). Em relação a este último, destaca-se a regulamentação por meio da Lei no 11.346/2006, conhecida como Lei da Segurança Alimentar, prevendo o direito de todos ao acesso de alimentos de qualidade, com o incentivo a práticas alimentares saudáveis e ambientalmente sustentáveis (artigo 3으).

Neste sentido, a Organização das Nações Unidas elaborou relatório, no ano de 2017, que defende a necessidade da redução gradativa do uso de agrotóxicos, com o objetivo de conferir maior proteção aos direitos à saúde e ao meio ambiente, fazendo referência aos tratados supramencionados (ONU, 2017). Também, a ONU emitiu nota direcionada ao governo brasileiro, demonstrando preocupação com a escalada, no legislativo nacional, do Projeto de Lei que facilitaria um maior uso de agrotóxicos (ONU, 2018).

O artigo começa analisando, numa perspectiva histórica, o uso de agrotóxicos no Brasil e a interferência do capital na agricultura; na sequência, debruça-se, de forma breve, sobre o arcabouço jurídico interno e internacional, hoje vigente, no que diz respeito aos direitos fundamentais à saúde, ao meio ambiente e à alimentação, e sua relação com o uso de agrotóxicos; passa-se, depois, à análise de proposições contidas no "Pacote do Veneno", no sentido da flexibilização da regulamentação do uso de agrotóxicos e do parecer favorável à sua aprovação; A partir daí, é possível analisar impactos da reforma legislativa na garantia dos direitos à saúde e ao meio ambiente.

O método utilizado para a pesquisa foi a análise de conteúdo, mais precisamente a análise do discurso do Legislativo na redação do Projeto de Lei 6.299/2002 e seus apensos, bem como do relatório da Comissão Especial, elaborado pelo deputado estadual Luiz Nishimori. Vale-se, também, da pesquisa documental da legislação nacional e internacional, além de relatórios de órgãos internacionais relacionados ao tema. Tudo isso, complementado pela pesquisa bibliográfica, com a utilização de produção científica crítica sobre a matéria.

Aferiu-se, como resultado da pesquisa, que as pretendidas alterações legislativas acabam por atuar como expediente para corroborar com a concentração de capital e poder nas mãos do agronegócio, em prejuízo de direitos humanos fundamentais.

\section{UM BREVE HISTÓRICO DO USO DE AGROTÓXICOS NO BRASIL E A INTERFERÊNCIA DO CAPITAL NA AGRICULTURA}

A produção agrícola, em grandes propriedades, na forma de monocultura, voltada à exportação, é a marca de nossa história. Vem da colônia, especialmente da exploração portuguesa de nossas terras para a produção açucareira, com a utilização de grandes extensões de terra e mão de obra escrava (FURTADO, 1999).

$\mathrm{O}$ atual modelo de agronegócio no Brasil, com a continuidade das monoculturas e o uso intensivo de agrotóxicos, remete às mudanças ocorridas no século 20, no qual se desenvolveram as tecnologias e o contexto histórico e social que transformaram a agricultura. A chamada "Revolução Verde" teve seu início após o final da Segunda Guerra Mundial, com a promessa de utilizar novas tecnologias para a erradicação da fome e aumentar a produtividade agrícola (DUNCK, 2015).

Durante o período da produção de armas químicas para a guerra, descobriu-se que as substâncias utilizadas matavam os insetos que eram usados nos testes. Assim, o resultado foi a criação de uma série de inseticidas sintéticos que passariam a ser empregados na agricultura. (CARSON, 2013). Dessa forma, a indústria de químicos da guerra encontrou um novo mercado para a venda de seu produto (LONDRES, 2011). Essa foi uma solução sobretudo para a indústria bélica, uma vez que os estoques de armas químicas e estrutura das fábricas foram adaptados em agrotóxicos e maquinário para a agricultura (FOLGADO, 2016a). 
Ainda neste contexto, foram criados organismos internacionais para difundir o "pacote tecnológico" da Revolução Verde principalmente para os países de economia mais voltada para a produção agrícola. Entre eles estão, por exemplo, o Banco Mundial, a Organização Mundial do Comércio e o Organismo das Nações Unidas para a Alimentação e Agricultura (FOLGADO, 2016a), além de fundações sem fins lucrativos, como a Rockefeller e a Ford, que também participaram do financiamento de centros de pesquisa (ALBERGONI; PELAEZ, 2007).

Diante deste contexto mundial, durante a presidência de Juscelino Kubitschek, no Brasil, o nacional desenvolvimentismo resultou em uma "aliança" entre a indústria e o setor agropecuário (DUNCK, 2015), o que possibilitou o crescimento dos dois setores. Assim, a partir de então, a intervenção do capital na agricultura se deu de forma mais acentuada.

Este capital é o do complexo industrial e comercial alimentar, situado como avalista dos produtores rurais. Este capital impõe ao produtor agrícola um programa de trabalho preciso, através da padronização dos produtos, extensão da transformação industrial, concentração de redes de coleta e comercialização (DUNCK, 2015, p. 224).

A intervenção da indústria na agricultura, aliada à "Revolução Verde", que ocorria em âmbito global, ocasionou o uso, em grande escala, de agrotóxicos no país (DUNCK, 2015). Sobretudo a partir da década de 60 , a substituição do trabalho humano pelo maquinário e o emprego dos produtos químicos foram vendidos pela indústria como a melhor alternativa para o controle de pragas e aumento da produtividade (DUNCK, 2015).

É importante esclarecer que a Revolução Verde, ao promover a utilização de novas tecnologias na agricultura, promoveu, também, o aumento da desigualdade. Somente os grandes produtores tinham acesso às novas ferramentas e produtos diante da nova lógica de mercantilização, fato que contribuiu para a concentração fundiária e êxodo rural em razão da impossibilidade de subsistência dos pequenos produtores e trabalhadores, agora substituídos pelo novo maquinário (JESUS; OMMATI, 2017). Além do mais, a promessa de acabar com a fome mundial jamais foi cumprida. No Brasil, a agricultura familiar perde de vez seu espaço para as grandes monoculturas, e a produção não é voltada para abastecer o mercado interno, mas para exportação (LAZZARI; SOUZA, 2017).

Ainda na mesma década, mais precisamente no ano de 1965 durante a Ditadura Militar, foi criado, pelo governo, o Sistema Nacional de Crédito Rural, instituído pela Lei no 4.829 de 1965, "que vinculava a obtenção de crédito agrícola à obrigatoriedade da compra do pacote tecnológico que trazia consigo os insumos químicos (agrotóxicos e fertilizantes)" (FOLGADO, 2016a, p. 257-258). Tal modelo criava a modalidade de crédito de custeio, com sua vinculação à utilização de sementes selecionadas, que pressupunham o uso de insumos agrícolas (KAGEYAMA, 1996). A citada Lei definia como objetivo da criação do Crédito Rural, entre outros:

Art. 3ㅇ São objetivos específicos do crédito rural: I - estimular o incremento ordenado dos investimentos rurais, inclusive para armazenamento beneficiamento e industrialização dos produtos agropecuários, quando efetuado por cooperativas ou pelo produtor na sua propriedade rural (BRASIL, 1965).

Já em 1975, o uso de agrotóxicos ganhou ainda mais força com a criação do Programa Nacional de Defensivos Agrícolas, no âmbito do II Programa Nacional de Desenvolvimento, que trouxe para o Brasil indústrias de fabricação dos insumos químicos (FOLGADO, 2016a).

Neste período ainda não existia uma Lei específica em âmbito federal para o controle e a regulamentação da compra, venda e uso de agrotóxicos. Havia, no entanto, o Decreto № 24.114 de 12 de abril de 1934 (Regulamento de Defesa Sanitária Vegetal), que estabelecia algumas regras para a fiscalização de fungicidas e pesticidas e para a obtenção do registro desses produtos, com validade máxima de 5 anos (artigos 52 a 75); bem como algumas Leis Estaduais específicas, com destaque para o Rio Grande do Sul, com a Lei Estadual no 7.747 de 1982 e a determinação, entre outras, de que a comercialização de qualquer agrotóxico deveria ser submetida ao cadastro prévio no Departamento de Meio Ambiente da Secretaria Estadual da Saúde e do Meio Ambiente (FOLGADO, 2016b). 
A Lei Federal dos Agrotóxicos (Lei no 7.802/1989) foi aprovada no Brasil somente em 1989 e, posteriormente, regulamentada pelo Decreto no 4.074 de 2002, que estabeleceu critérios mais rígidos do que os anteriormente existentes para o registro e uso dos agrotóxicos (PELAEZ; TERRA; SILVA, 2010). O uso de agrotóxicos, no entanto, continuou aumentando ao longo dos anos.

Conforme dados divulgados pelo Sindicato Nacional da Indústria de Produtos para Defesa Agrícola (Sindag) e pela Associação Nacional de Defesa Vegetal (Andev), entre os anos de 2011 e 2012 houve um aumento de $14 \%$ nas vendas de defensivos agrícolas no Brasil, e de 2000 a 2012 o aumento total na comercialização de agrotóxicos foi de 162,32\% (CARNEIRO et al., 2015).

Ainda, o incentivo governamental ao uso de agrotóxicos perdura até hoje, apesar da previsão constitucional de proteção à saúde e ao meio ambiente e da existência de uma legislação específica. Além da redução na alíquota do ICMS para a circulação de pesticidas, o Decreto no 5.630, de 22 de dezembro de 2005, até hoje vigente, reduz a zero a alíquota da Contribuição para o PIS/Pasep e da Contribuição para o Financiamento da Seguridade Social - Cofins para os produtos "classificados na posição 38.08 da NCM e suas matérias-primas" (LONDRES, 2011, p. 18):

A posição 3808 da NCM (Nomenclatura Comum do Mercosul) compreende produtos diversos das indústrias químicas como inseticidas, fungicidas e herbicidas. Além das isenções federais, há as isenções complementares determinadas por alguns estados. No Ceará, por exemplo, a isenção de ICMS, IPI, COFINS e PIS/PASEP para atividades envolvendo agrotóxicos chega a 100\% (p. 19).

No ano de 2016, o Partido Socialismo e Liberdade - PSOL - ingressou com Ação Direta de Inconstitucionalidade no Supremo Tribunal Federal (ADI 5553) para questionar a redução de $60 \%$ na base de cálculo do Imposto sobre Circulação de Mercadorias e Serviços para agrotóxicos, bem como a isenção do Imposto Sobre Produtos Industrializados, tendo em vista que são substâncias tóxicas, de modo que o incentivo fiscal viola os direitos fundamentais à saúde e ao ambiente equilibrado. A Ação, no entanto, ainda aguarda julgamento (BRASIL, 2016).

Por fim, é preciso esclarecer que o mercado dos agrotóxicos assumiu caraterísticas de oligopólio. No ano de 2007, por exemplo, as seis maiores empresas - Bayer, Syngenta, Basf, Monsanto, Dow e DuPont - concentravam $86 \%$ de toda a comercialização mundial de veneno (LONDRES, 2011, p. 20). No ano de 2017, as empresas Dow e Dupont fundiram-se na nova DowDuPont, e, além disso, a Syngenta foi comprada pela empresa ChemChina. Em 2018, por fim, a Monsanto foi comprada pela Bayer, transformando-se na "maior corporação agrícola do mundo" (SANTOS; GLASS, 2018, p. 20). "Assim, os três conglomerados recém-formados devem dominar mais de $60 \%$ do mercado de sementes comerciais e de agrotóxicos" (SANTOS; GLASS, 2018, p. 20).

\section{DIREITOS HUMANOS À SAÚDE, À SEGURANÇA ALIMENTAR E AO MEIO AMBIENTE E A REGULAÇÃO DO USO DE AGROTÓXICOS NO BRASIL}

A Convenção no 155, da Organização Internacional do Trabalho, ratificada pelo Brasil em 1992, que trata da segurança e saúde dos trabalhadores no ambiente laboral, estabelece, em seu artigo 4으, que os países signatários têm a obrigação de adotar políticas de promoção de maior segurança no ambiente de trabalho para a prevenção de acidentes e danos à saúde.

Da mesma forma, há também a Convenção de Roterdã (Convenção sobre Procedimento de Consentimento Prévio Informado para o Comércio Internacional de Certas Substâncias Químicas e Agrotóxicos Perigosos), promulgada no Brasil pelo Decreto no 5.360, de 31 de janeiro de 2005, que trata de regramentos para o comércio internacional de agrotóxicos, e, já em suas considerações iniciais, leva em conta os riscos trazidos pelas substâncias químicas e a necessidade de se proteger a saúde e o meio ambiente contra esses impactos.

A Convenção de Estocolmo, também promulgada em 2005 pelo Decreto $n=5.472$, leva em conta o princípio da precaução e estabelece, em seu artigo 1ำ, que seu objetivo é a proteção do meio ambiente contra os possíveis danos causados pelos agrotóxicos e, em seu artigo 4으, determina que é dever de cada Estado Parte adotar medidas de regulamentação a fim de reduzir ou eliminar a produção e utilização de determinados agrotóxicos. 
A Organização das Nações Unidas, por meio do Conselho de Direitos Humanos, no ano de 2017 emitiu o Relatório sobre o Direito à Alimentação, no qual trata do uso dos pesticidas na agricultura e seus impactos sobre os direitos humanos com a seguinte passagem:

Exposição a pesticidas pode causar severos impactos na fruição dos direitos humanos, em particular o direito à alimentação adequada, bem como o direito à saúde. O direito à alimentação obriga os Estados a implementarem medidas de proteção e requisitos de segurança alimentar para assegurar que a comida é segura, livre de pesticidas e de qualidade adequada. Além do mais, os padrões de direitos humanos demandam que os Estados protejam grupos vulneráveis, como trabalhadores rurais e comunidades agrícolas, crianças e mulheres grávidas dos impactos dos agrotóxicos (ONU, 2017, p. 4, tradução livre).

De igual modo, o Pacto Internacional sobre Direitos Econômicos, Sociais e Culturais, promulgado pelo Brasil em 1992, em seu artigo 11 estabelece o direito à alimentação adequada, com a indicação de que os Estados partes deverão adotar medidas para assegurar o exercício de tal direito.

Por fim, a Declaração do Rio Sobre Meio Ambiente e Desenvolvimento, documento elaborado quando da Conferência das Nações Unidas sobre Meio Ambiente e Desenvolvimento, ocorrida em 1992, trouxe o chamado princípio da precaução:

Princípio 15: Com o fim de proteger o meio ambiente, o princípio da precaução deverá ser amplamente observado pelos Estados, de acordo com suas capacidades. Quando houver ameaça de danos graves ou irreversíveis, a ausência de certeza científica absoluta não será utilizada como razão para o adiamento de medidas economicamente viáveis para prevenir a degradação ambiental (CONFERÊNCIA..., 1992).

Já no âmbito do direito interno, a Constituição Federal de 1988 traz dispositivos para proteção sobretudo à saúde e ao meio ambiente, que, por si só, norteiam para a necessidade da redução do uso de pesticidas. Dispõe no artigo 225: "Todos têm direito ao meio ambiente ecologicamente equilibrado, bem de uso comum do povo e essencial à sadia qualidade de vida, impondo-se ao Poder Público e à coletividade o dever de defendê-lo e preservá-lo para as presentes e futuras gerações" (BRASIL, 1988).

De igual modo, o artigo 6o prevê a alimentação como direito fundamental. Tal proteção foi consolidada também pela Lei no 11.346/2006 (Lei Orgânica de Segurança Alimentar e Nutricional) que, em seu artigo 3으, define segurança alimentar e nutricional como o acesso de todos a alimento de qualidade, com base em práticas alimentares "que respeitem a diversidade cultural e que sejam ambiental, cultural, econômica e socialmente sustentáveis." É importante salientar, portanto, que a segurança alimentar não se concretiza somente com o acesso à alimentação, mas também pela garantia de alimento de qualidade (JESUS; OMMATI, 2017, p. 207).

O artigo 196 da Constituição Federal também estabelece o direito à saúde, com a determinação de que se adotem políticas de prevenção ao risco de doenças. Por fim, a Lei de Agrotóxicos (Lei no 7.802 de 1989), traz definições importantes. Entre elas, seu texto utiliza a palavra "agrotóxico" com a seguinte definição:

Art. 2ㅇ Para os efeitos desta Lei, consideram-se: I - agrotóxicos e afins: a) os produtos e os agentes de processos físicos, químicos ou biológicos, destinados ao uso nos setores de produção, no armazenamento e beneficiamento de produtos agrícolas, nas pastagens, na proteção de florestas, nativas ou implantadas, e de outros ecossistemas e também de ambientes urbanos, hídricos e industriais, cuja finalidade seja alterar a composição da flora ou da fauna, a fim de preservá-las da ação danosa de seres vivos considerados nocivos.

O termo também é o utilizado pela Constituição Federal, em seu artigo 220, § 4ㅇ. Tal nomenclatura demonstra preocupação e atenção para o potencial tóxico destas substâncias, ao contrário de termos como "defensivos agrícolas" ou "produtos fitossanitários" (FOLGADO, 2016b).

Ainda, o Decreto no 4.074 de 2002, que regulamenta a Lei de Agrotóxicos, define também, em seu artigo 2으, a competência tripartite para a avaliação, fiscalização e registro de agrotóxicos, que é exercida pelos Ministérios da Saúde, do Meio Ambiente e da Agricultura. Essa repartição é importante, pois garante que nenhum interesse prevalecerá, uma vez que cada órgão fará a análise de acordo com sua área respectiva (FOLGADO, 2016b). 


\section{O PACOTE DO VENENO E O DEBATE NO CONGRESSO}

\subsection{O Projeto de Lei no 6.299/2002 e seus Apensados}

O Projeto de Lei no 6.299/2002 é o resultado de articulações da bancada ruralista que, há muito, buscam flexibilizar ainda mais a legislação brasileira existente para a regulamentação do uso de agrotóxicos (FRIEDRICH; SOUZA; CARNEIRO, 2018).

O chamado "Pacote do Veneno" é uma reunião de diversos Projetos de Lei que estavam em trâmite no Congresso Nacional entre os anos de 1999 e 2017 (PORTO, 2018). Em junho de 2018, o Projeto de Lei no $6.299 / 2002$ e seus apensados passaram por avaliação da Comissão Especial, que deliberou por sua aprovação, e atualmente aguarda votação em plenário.

Uma das proposições do Pacote do Veneno é a alteração da nomenclatura atualmente utilizada de "agrotóxicos" para o termo "produtos fitossanitários" ou "produtos de controle ambiental". Tal alteração vem prevista pelo artigo 5o do PL 3.200/2015, que assim define produto fitossanitário:

Inciso XXXIV - produto defensivo fitossanitário - produto e agente de processos físicos, químicos ou biológicos, destinado ao uso nos setores de produção, no armazenamento e beneficiamento de produtos agrícolas, nas pastagens, na proteção de florestas plantadas cuja finalidade seja alterar a composição da flora ou da fauna, a fim de preservá-las da ação danosa de seres vivos considerados nocivos.

Segundo Nota Técnica emitida pela Fiocruz, essa mudança traz consigo o ocultamento dos riscos da utilização de pesticidas, com uma sensação falsa de segurança e tentativa de supressão do entendimento de que os agrotóxicos são, essencialmente, produtos tóxicos. Essa nova nomenclatura também está em desacordo com a literatura internacional sobre o tema, que denomina pesticidas, praguicidas ou agrotóxicos destacando o potencial de toxicidade destes produtos (FIOCRUZ, 2018).

A utilização de "produto fitossanitário" vem com uma carga ideológica de omissão dos riscos trazidos por estes produtos, com motivação obviamente econômica e sem qualquer responsabilidade no que diz respeito à proteção e prevenção da saúde e do meio ambiente (FOLGADO, 2016b).

Ainda, no artigo 1 ㅇ do PL 6.299/2002, há a proposta de retirada dos produtos utilizados em ambiente urbano ou industrial da regulamentação da Lei dos Agrotóxicos, que passarão a ser regidos pela Lei 6.330/1976 - que dispões sobre a Vigilância Sanitária de medicamentos, insumos farmacêuticos, etc. Essa alteração pretende perpetrar o entendimento de que os produtos feitos a partir das mesmas substâncias dos agrotóxicos, mas que não são usados na agricultura, não possuem a mesma toxicidade e não devem ser tratados com o mesmo rigor (FIOCRUZ, 2018).

Enquanto a legislação atual, Lei no 7.802/1989, em seu artigo 3o, parágrafo 6으, alínea c, estabelece que é proibido o registro de qualquer agrotóxico que apresente características "teratogênicas, carcinogênicas, mutagênicas", no artigo 2으, inciso VI, artigo 3ㅇ, § 15 e artigo 4으, § 3ㅇ do Projeto de Lei, é introduzido o termo "risco inaceitável" para a comercialização de agrotóxicos. Segundo o texto legislativo:

Artigo 4ㅇ (...) §3ㅇ: fica proibido o registro de produtos fitossanitários, de produtos de controle ambiental e afins que, nas condições recomendadas de uso, apresentem risco inaceitável para os seres humanos ou para o meio ambiente, ou seja, permanece inseguro mesmo com a implementação das medidas de gestão de risco.

A partir do texto do artigo supracitado, percebe-se que, caso aprovado o $\mathrm{PL}$, qualquer agrotóxico que for considerado de "risco aceitável" estará passível de autorização (FIOCRUZ, 2018), e somente será proibido o uso de produto que apresenta "risco inaceitável". O texto do Projeto de Lei, entretanto, não define o que se entende por risco inaceitável (ALMEIDA et al., 2017). Além do mais, estabelecer quando uma substância apresenta risco inaceitável é tarefa extremamente complexa:

A Organização Mundial da Saúde (OMS) estabelece que se uma substância é considerada comprovadamente carcinogênica para animais, deve também ser tratada como tal para seres humanos, principalmente se também tem ação genotóxica (mutagênica, ou seja, apresentar mutações dos genes). Frequentemente considera-se que uma única molécula capaz de produzir efeito adverso, como câncer ou mutação genética, é suficiente para iniciar um processo que, progressivamente, pode levar ao efeito prejudicial observado. Por essa razão, 
não é possível demonstrar que existe um limite seguro de exposição para um agente causador de câncer (carcinogênico) ou de mutação genética (mutagênico). Portanto, não existe a possibilidade de estabelecer parâmetro de "risco inaceitável" para substâncias genotóxicas (ALMEIDA et al., 2017, p. 6).

Além do mais, a redação proposta para o artigo 3으, dos parágrafos 60 ao 10 , cria o que chama de Registro Temporário e Autorização Temporária para os "Produtos Técnicos, Produtos Técnicos Equivalentes, Produtos Novos, Produtos Formulados e Produtos Genéricos", para os produtos que estejam registrados em pelo menos outros três países que sejam membros da Organização para a Cooperação e Desenvolvimento Econômico e adotam o Código Internacional de Conduta sobre a Distribuição e Uso de Pesticidas da Organização das Nações Unidas para Alimentação e Agricultura.

O registro/autorização será concedido para os casos em que os órgãos responsáveis pela Agricultura, Meio Ambiente e Saúde não emitirem manifestação conclusiva quanto ao produto no prazo de 12 meses para produto novo ou 180 dias para alterações. Esse prazo também é estabelecido pelo Projeto de Lei 6.299/2002, em seu artigo $3 \circ$, $§ 1$.

O registro/autorização temporários, quando concedidos, desconsideram a atuação das agências reguladoras nacionais e deixam de levar em conta as peculiaridades de cada local, que acabam influenciando o grau de toxicidade de cada pesticida. É preciso também considerar que, caso ao final da análise os órgãos reguladores emitam parecer negativo, será muito difícil reverter os danos já causados pelo uso daquele determinado agrotóxico pelo tempo da autorização/registro temporário (FIOCRUZ, 2018).

Outra alteração proposta diz respeito à determinação de que o poder público deverá buscar a desburocratização e simplificação para as análises dos processos de registro (artigo 3ㅇ, §22 e artigo 4ำ, VIII), e uma das alterações mais significativas do Pacote do Veneno está no artigo 4a da proposta, que diz:

Art. 40: Fica estabelecido o órgão federal responsável pelo setor da agricultura como órgão registrante dos produtos fitossanitários e afins, assim como o órgão federal que atua na área de meio ambiente como o órgão registrante de produtos de controle ambiental, seus produtos técnicos e afins.

Consoante a regulamentação atual, dada pelo Decreto no 4.074, de 4 de janeiro de 2002, para a concessão do registro de um produto agrotóxico é realizada uma avaliação tripartite pelo Ministério da Saúde, que, por meio da Anvisa, avalia o nível de toxicidade para a saúde humana, Ministério do Meio Ambiente, pelo Ibama, que faz a avaliação ecotoxicológica e o Ministério da Agricultura, Pecuária e Abastecimento, para avaliação da eficácia agronômica (FIOCRUZ, 2018).

Caso aprovada a mudança, a competência para avaliação da toxicidade e aprovação do registro seria tão somente do Ministério da Agricultura, Pecuária e Abastecimento, "promovendo um verdadeiro desmonte no sistema de regulação tríplice", e a Anvisa terá somente participação consultiva (FIOCRUZ, 2018).

Outras alterações que retiram poder de decisão dos Ministérios da Saúde e do Meio Ambiente estão no Capítulo III do PL 3.200/2015. O artigo 6o estabelece que estará autorizada a criação, no âmbito do Ministério da Agricultura, da Comissão Técnica Nacional de Fitossaniários (CNTFito), com competência consultiva e deliberativa para apresentar pareceres conclusivos sobre os pedidos de avaliação de novos agrotóxicos, aqui tratados como "produtos fitossanitários, de controle ambiental, seus produtos técnicos e afins". Ainda, conforme a proposta do artigo 7으, o Conselho será composto por 23 membros indicados pelo Ministro da Agricultura, Pecuária e Abastecimento (ALMEIDA et al., 2017, p. 4).

Sendo assim, o PL propõe uma concentração de poder no âmbito da CTNFito, vinculada ao MAPA, excluindo diversas atribuições específicas do Ministério da Saúde e MMA (ALMEIDA et al., 2017, p. 4).

Já com a mudança no artigo 9o, parágrafo único, segundo a proposta, os Estados e o Distrito Federal ficarão vedados de estabelecer normas mais restritivas para a comercialização dos produtos registrados (FIOCRUZ, 2018). Ainda, de acordo com a alteração proposta no artigo 16, haverá a possibilidade de as instituições representativas dos agricultores solicitarem ao órgão registrante federal autorização para estender o uso dos agrotóxicos registrados para seu emprego em outras culturas que tenham "suporte fitossanitário insuficiente".

O artigo 17 da proposta dispõe que, quando a produção dos "produtos fitossanitários" for destinada exclusivamente à exportação, estes ficarão desobrigados de fazer o registro no órgão registrante, bem como estará dispensada a apresentação dos estudos agronômicos, toxicológicos e ambientais. Tal mudança reflete 
a negligência com a saúde dos trabalhadores na produção destes produtos. Apesar de os mesmos não serem utilizados no território nacional, os efeitos tóxicos ocorrem também em seu processo de produção (FIOCRUZ, 2018).

Destaca-se que o risco de exposição dos trabalhadores não é eliminado pelo simples uso de equipamentos de proteção individual (EPI). Diversos estudos indicam a baixa eficiência dos EPI, permitindo que os trabalhadores entrem em contato com os agrotóxicos, inclusive nos procedimentos de vestir e despir as vestimentas (FIOCRUZ, 2018).

Já o artigo 18 do Projeto de Lei 6.299/2002 estatui que não haverá necessidade de registro para os agrotóxicos quando houver declaração do "estado de emergência fitossanitária pelo poder executivo", de modo que o órgão registrante estará autorizado a emitir permissão emergencial temporária para produção, comercialização e uso (FIOCRUZ, 2018). Ainda, o artigo 54 do PL 3.200/2015 vem estabelecer a possibilidade de prescrição de receita agronômica de forma preventiva, ou seja, antes da ocorrência da praga. Neste sentido,

A aplicação preventiva contribui para o uso intensivo de agrotóxico, empobrece a biodiversidade benéfica às culturas, gerando resistências de espécies aos agrotóxicos, além de contribuir para a contaminação do solo, das águas, pela lixiviação e carregamento destes compostos, e dos trabalhadores pela bioacumulação ao longo do tempo (ALMEIDA et al., 2017, p. 6).

\subsection{O Parecer Favorável do Então Deputado Luiz Nishimori}

No Parecer da Comissão Especial de avaliação do Projeto de Lei 6.299 de 2002 junto a seus apensados, emitido em 2018 e assinado pelo então deputado federal Luiz Nishimori, membro da Frente Parlamentar da Agropecuária, trata-se do esgotamento da regulamentação proposta pela Lei no 7.802, de 1989, motivo pelo qual as alterações propostas são, em tese, necessárias (BRASIL, 2018). Para tanto, o deputado elencou três fatores que devem ser considerados:

(I) uma série de acordos e tratados internacionais científicos que foram celebrados em data posterior a edição da Lei 7.802/1989. Comandos e princípios da Lei 7.802/1989 estão defasados cientificamente, criando enormes distorções, causando prejuízos e insegurança; (II) os procedimentos de análise, registro e de reanálise dos pesticidas têm-se revelado onerosos e demorados, em razão da burocracia e falta de investimentos em pesquisa científica e estrutura para atender os agentes envolvidos na cadeia produtiva; (III) aspectos inerentes à agricultura tropical especialmente quanto à atuação de patógenos e sua biologia são desconsiderados. Os órgãos federais da agricultura, da saúde e do meio ambiente não conseguem responder adequadamente aos desafios biológicos e químicos, diante dos processos de resistência aos pesticidas (BRASIL, 2018, p. 16).

Ainda, menciona o relatório que o território nacional, por ser de clima tropical, está mais sujeito ao surgimento de pragas na agricultura, além da grande diversidade dos organismos e da capacidade de adaptação das pragas (BRASIL, 2018).

Outra questão levantada é a suposta obsolescência da legislação atual em relação aos Tratados Internacionais assinados posteriormente pelo Brasil, bem como a regulamentação vigente em outros países. Conforme o relatório, a reforma proposta pelo Projeto de Lei irá adequar o sistema nacional, por exemplo ao Acordo sobre Medidas Sanitárias e Fitossanitárias - SPS -, que "tem como objetivo garantir que as medidas sanitárias e fitossanitárias, elaborados por países-membros da OMC, não se transformem em obstáculos desnecessários ao comércio" (BRASIL, 2018, p. 19). Segundo o parecer, a estrutura para registro de novos "produtos fitossanitários", no Brasil, é demasiadamente burocrática, fator prejudicial ao combate efetivo das pragas que se tornam resistentes aos agrotóxicos então existentes (BRASIL, 2018).

O relator também defende a modificação do termo "agrotóxico". Em seu entendimento, a palavra é inadequada, pois confere ao produto uma conotação negativa perante a população, quando, na verdade, o termo correto deveria ser "pesticida", vocábulo que significa algo como o que mata enfermidades (BRASIL, 2018).

O parecer faz, ainda, uma crítica ao método brasileiro que se baseia, hoje, na avaliação do perigo que um agrotóxico pode causar, enquanto a maioria dos países, ao contrário, faz uma avaliação de risco. Neste sentido, o risco possui dois componentes - o perigo e a exposição -, posto que ambos serão levados em consideração para se chegar à determinação se o risco é aceitável ou não (BRASIL, 2018). Assim, 
A “identificação do perigo" consta na Lei no 7.802/1989, sempre foi usada no Brasil e é, atualmente, indicada pelos países da União Europeia como o ideal para o registro de agrotóxicos. O "perigo" é definido como "a propriedade inerente de um agente químico com potencial de causar efeitos tóxicos sobre a saúde humana e o meio ambiente". Já o "risco" é a "probabilidade de ocorrência de um efeito tóxico para a saúde humana e o meio ambiente" e a "análise de riscos" proposta é um processo constituído de três etapas que vai fixar um "limite permitido de exposição" aos agrotóxicos, que desconsidera as seguintes questões: a periculosidade intrínseca dos agrotóxicos, o fato de não existir limites seguros de exposição a substâncias mutagênicas e carcinogênicas e o Princípio da Precaução (FRIEDRICH; SOUZA; CARNEIRO, 2018, p. 40).

Apesar de, no entanto, em seu discurso mencionar que as propostas aprovadas pela Comissão irão, além de promover a adequação da legislação brasileira aos padrões internacionais, também garantir a proteção à saúde e ao meio ambiente por meio da análise de riscos, o relator opinou pela rejeição dos Projetos de Lei apensados que propunham a proibição dos agrotóxicos que possuam em sua composição ácido 2,4 - diclorofenoxiacetico, glifosato, clotianidina, tiametoxam ou imidacloprido, além dos que possuem 19 ingredientes ativos (Projetos de Lei nos 713/1999, 1.388/1999, 7.564/2006, 4.412/2012, 2.129/2015 e 5.218/2016) (BRASIL, 2018).

\section{O PACOTE DO VENENO E O PARECER DA COMISSÃO ESPECIAL: Expediente para o Crescimento Econômico do Agronegócio e Violações aos Direitos Humanos}

Tendo em vista que é dever do Estado zelar pela proteção à saúde e ao meio ambiente, passamos a analisar os impactos que o uso de agrotóxicos para a produção agrícola pode produzir sobre estes direitos fundamentais.

No livro Primavera Silenciosa, publicado ainda em 1962, a bióloga Rachel Carson trata dos diversos riscos do uso de agrotóxicos para a saúde e para o meio ambiente. No capítulo "Elixires da Morte", enfatiza que os pesticidas sintéticos têm uma grande "potência biológica", de modo que seu potencial de contaminação pode prejudicar inclusive o funcionamento vital do organismo humano (CARSON, 2013).

Os efeitos dos agrotóxicos na saúde podem ser classificados em agudos ou crônicos, sendo os agudos aqueles que aparecem em até 24 horas após a exposição ao veneno. Os efeitos crônicos surgem após exposição continuada a doses baixas dos produtos. Por exemplo, a exposição aos pesticidas do grupo químico dos organofosforados e carbamatos pode apresentar, como efeito agudo, vômitos, convulsões e espasmos musculares, e, como efeitos crônicos, alterações cromossômicas e efeitos neurotóxicos retardados (PERES; MOREIRA; DUBOIS 2003).

Ainda, diversos tipos de agrotóxicos apresentam efeitos negativos sobre a saúde reprodutiva, tanto em animais quanto em humanos; alguns também podem alterar o funcionamento da tireoide e, a longo prazo, contribuir para o aparecimento de câncer (PERES; MOREIRA; DUBOIS, 2003).

Já com relação ao meio ambiente, o uso de agrotóxicos causa contaminação, por exemplo, de espécies de seres vivos que não são o alvo de sua atuação. Esse impacto pode causar um desequilíbrio no ecossistema (PERES; MOREIRA; DUBOIS, 2003).

Outra questão de grande importância é a contaminação das águas superficiais e subterrâneas. A contaminação da água acarreta a contaminação também de peixes e demais animais aquáticos e, por consequência, dos seres humanos que os ingerirem (PERES; MOREIRA; DUBOIS, 2003); esse tipo de contaminação é especialmente danoso porque as substâncias tóxicas, por meio da água, são carregadas para outros lugares:

Se uma região agrícola, onde se utiliza extensivamente uma grande quantidade ou variedade de agrotóxicos, estiver localizada próxima a um manancial hídrico que abasteça uma cidade, a qualidade da água ali consumida estará seriamente sob o risco de uma contaminação, embora a mesma possa estar localizada bem distante da região agrícola (PERES; MOREIRA; DUBOIS, 2003, p. 38).

Para se ter uma dimensão do grau de contaminação por agrotóxicos nos alimentos produzidos no Brasil, o Programa de Análise de Resíduos de Agrotóxicos em Alimentos (Para) publicou relatório, no ano de 2016, com a informação de que, entre 12.051 amostras de 25 alimentos de origem vegetal, 2.371 delas foram consideradas insatisfatórias em razão da alta concentração de agrotóxicos (ANVISA, 2016). 
Preocupada com a possível aprovação do Projeto de Lei no 6.299/2002, a Organização das Nações Unidas emitiu nota dirigida ao Estado Brasileiro, listando as principais inquietudes no que diz respeito às propostas do Pacote do Veneno (ONU, 2018).

O primeiro alerta feito diz respeito às novas regras propostas para o registro, uso e comercialização de pesticidas, que, como mostrado no capítulo anterior, irá concentrar somente no Ministério da Agricultura o encargo de registrar os agrotóxicos no Brasil. Segundo o texto, a preocupação é de que, com seu enorme poder financeiro, o agronegócio teria mais facilidade para controlar as decisões do órgão (ONU, 2018).

Ainda, a nota menciona o perigo da autorização e uso de pesticidas que, possivelmente, causam câncer, malformações congênitas e outros problemas ligados à saúde, uma vez que, conforme a mudança de texto legal proposta, somente serão proibidos os agrotóxicos que apresentem "risco inaceitável". O critério baseado na aceitabilidade dos riscos, conforme já atestado em outros países, tende a falhar na proteção aos grupos de maior risco, como as crianças, trabalhadores e comunidades de baixa renda (ONU, 2018).

Conforme o mesmo documento, o país continua oferecendo estímulo financeiro para a compra de pesticidas, enquanto em outros países verificou-se o sucesso de políticas que, ao contrário, visam a reduzir o uso dos agrotóxicos (ONU, 2018).

Em nota técnica lançada pelo Ministério Público Federal, o Órgão apontou diversas inconstitucionalidades no Projeto de Lei 6.299 de 2002, sobretudo no que se refere à proteção aos direitos à saúde e ao meio ambiente (MINISTÉRIO..., 2018). O primeiro exemplo citado é a própria definição de "gestão de riscos", no artigo 2ㅇ, $\mathrm{VI}$, "C":

A definição de gestão dos riscos como o “(...) processo, decorrente da avaliação dos riscos, que consiste em ponderar fatores políticos, econômicos, sociais e regulatórios bem como os efeitos sobre a saúde humana e meio ambiente (...)" (art. 2ㅇ, VI, "c") estabelece, de forma clara, a inversão das prioridades constitucionais estabelecidas no presente PL: a submissão do Direito à Saúde, ao Meio Ambiente e à defesa do consumidor à Ordem Econômica, especificamente à Política Agrícola (MINISTÉRIO..., 2018).

O documento ressalta, também, que, ao longo do texto, dos artigos propostos e das falas dos favoráveis à sua aprovação, muitas vezes observa-se a priorização da redução da burocracia e da necessidade de mais transparência, mas pouco se fala nos prejuízos que potencialmente serão causados à saúde e ao meio ambiente (MINISTÉRIO..., 2018).

Outra inconstitucionalidade mencionada pelo Ministério Público Federal diz respeito a violações ao artigo 170, inciso VI, artigo 196 e artigo 225, parágrafo 10, inciso V da Constituição. Todos estes dispositivos dizem respeito à redução de impacto ambiental e prevenção contra o risco de doenças. O Pacote do Veneno propõe, na contramão, a proibição de registro somente de agrotóxicos que apresentem "risco inaceitável", a possibilidade de registro e autorização temporários e a limitação das competências dos Ministérios da Saúde e do Meio Ambiente, com concentração das funções para o registro no Ministério da Agricultura (MINISTÉRIO..., 2018). Ainda, nota técnica emitida no mesmo sentido pela Defensoria Pública da União, constata:

Ao analisar o Projeto de Lei no 6.299/2002 e apensos, constata-se que, não obstante as justificativas que o originaram seja a desburocratização ou a liberação de agrotóxicos na velocidade da produção agrícola, essas disposições, formal e materialmente, ferem disposições constitucionais e de proteção no âmbito internacional (DEFENSORIA..., 2018).

Desta forma, conclui-se que, em realidade, o Pacote do Veneno vem para atender aos interesses mercadológicos do agronegócio e da indústria de agrotóxicos. Nas palavras de llena Felipe Barros (2018):

A hegemonia do agronegócio sustenta-se no modelo agroexportador de commodities, em grande escala e com uso intensivo de agrotóxicos e transgênicos, não permitindo outra forma de produção agrícola (p. 183).

Ora, a flexibilização da legislação que regulamenta o uso de veneno na agricultura interessa, portanto, à manutenção da mencionada hegemonia, posto que o uso abusivo de agrotóxicos acaba por aumentar a rentabilidade da produção (BARROS, 2018). 
O avanço do Pacote do Veneno explica-se, ainda, pela forte manipulação das prioridades do Poder Legislativos pelas forças hegemônicas do agronegócio. A chamada Bancada Ruralista é uma das mais antigas e organizadas das Frentes Parlamentares (SIMIONATTO; COSTA, 2012). Para manter sua hegemonia, o grupo utiliza-se de um poder de articulação com outros grupos de interesses que também pertençam à classe dominante, valendo-se dessa negociação para garantir a manutenção de seus interesses (SIMIONATTO; COSTA, 2012).

O próprio parecer legislativo pela rejeição aos Projetos de proibição de alguns venenos, conforme mencionamos no capítulo anterior, demonstra os reais interesses prevalecentes. Entre os motivos apresentados pelo deputado relator, em nenhum momento percebe-se uma real preocupação com a proteção aos direitos humanos. Assim, fica evidente que o que se busca é a manutenção do lucro da indústria de agrotóxicos e do agronegócio (FRIEDRICH; SOUZA; CARNEIRO, 2018).

Na verdade, entretanto, a produtividade não cresce proporcionalmente à quantidade de agrotóxicos utilizada, mas, o que se verifica, é que cada vez mais veneno é necessário para o cultivo da mesma quantidade. Esse fenômeno acontece na chamada "cadeia produtiva químico dependente". Por exemplo, em uma plantação de um hectare de soja são utilizados, hoje, 12 litros de veneno, posto que, há 10 anos, eram necessários somente 7 ou 8 (PIGNATI, 2016).

A afirmação difundida pelo agronegócio, desde a Revolução Verde, de que o uso de pesticidas é necessário para que a produção de alimentos seja suficiente para a população mundial, também é falaciosa. $O$ que se verifica é que a quantidade de alimentos produzida é suficiente para alimentar a todos, e na verdade acontece uma má distribuição (LONDRES, 2011). Neste sentido,

E, ao contrário do que tentam fazer crer as indústrias e os defensores do status quo social, existem infinitas experiências que mostram ser possível alcançar boas produtividades a baixíssimos custos através de sistemas ecológicos de produção (LONDRES, 2011, p. 23).

Estas formas alternativas, no entanto, não se encaixam no tradicional modelo do agronegócio, que destrói a biodiversidade em sua extensão. Os sistemas agroecológicos, por sua vez, são mais adequados ao modelo de agricultura familiar (LONDRES, 2011).

Desta maneira, a facilitação do uso de agrotóxicos irá atender a interesses particulares dos já detentores do capital, mediante sacrifício do interesse público de proteção dos direitos à saúde, à segurança alimentar $e$ ao meio ambiente (PELAEZ; TERRA; SILVA, 2010).

\section{CONSIDERAÇÕES FINAIS}

Diante de toda a análise apresentada verificamos que o discurso repetido incessantemente pela elite do agronegócio deve ser desmistificado. A promessa da Revolução Verde de que o pacote tecnológico, que incluía a aplicação de veneno na lavoura, viria a solucionar o problema da fome e aumentar a produtividade, caiu por terra, uma vez que já ficou mais que demonstrado que os prejuízos do uso de agrotóxicos são incalculáveis e sua utilização não acarreta, necessariamente, em maior produtividade. $O$ uso de agrotóxicos atende aos interesses do agronegócio, tão somente.

O discurso da dominação carrega, em si, a contradição da eterna promessa de uma vida melhor, que nunca chega, e a realidade experimentada por uma população que paga o preço pela chamada "busca pelo progresso" (CARNEIRO et al., 2015, p. 114).

A proposta do Projeto de Lei 6.299 de 2002 e seus apensados, sob o pretexto de desburocratizar e modernizar o sistema de regulamentação de agrotóxicos, desrespeita o mandamento constitucional de proteção à saúde e ao meio ambiente, bem como as previsões dos diversos tratados internacionais abordados no que diz respeito à proteção destes direitos humanos. Vem, em realidade, como meio para concretizar as ambições dos grandes latifundiários e donos de grandes indústrias produtoras de veneno, de manutenção do seu crescimento econômico e, em consequência, de seu status quo de dominação no sistema capitalista. 


\section{REFERÊNCIAS}

ALBERGONI, L.; PELAEZ, V. Da Revolução Verde à agrobiotecnologia: ruptura ou continuidade de paradigmas? Revista de Economia, 33 (1), p. 31-53, 2007. Disponível em: revistas.ufpr.br/economia/article/view/8546/6017. Acesso em: 7 mar. 2020.

ALMEIDA, M. D. et al. A flexibilização da legislação brasileira de agrotóxicos e os riscos à saúde humana: análise do Projeto de Lei no 3.200/2015. Cad. Saúde Pública, Rio de Janeiro, v. 33, n. 7, e00181016, 2017. Disponível em: www.scielo.br/scielo. php?script=sci_arttext\&pid=S0102-311X2017000703001\&lng=en\&nrm=iso. Acesso em: 14 abr. 2019.

ANVISA. Agência Nacional de Vigilância Sanitária. Programa de Análise de Resíduos de Agrotóxicos em Alimentos - PARA. Relatório das Análises de Amostras Monitoradas no Período de 2013 a 2015. Brasília, 25 de novembro de 2016. Disponível em: portal.anvisa.gov.br/documents/111215/0/Relat\%C3\%B3rio+PARA+2013-2015_VERS\%C3\%830-FINAL.pdf/494cd7c5-5408-4e6a-b0e5-5098cbf759f8. Acesso em: 14 abr. 2019.

BARDIN, L. Análise de conteúdo. São Paulo, SP: Edições 70, 2016.

BARROS, I. F. O agronegócio e a atuação da burguesia agrária: considerações da luta de classes no campo. Serv. Soc. Soc., São Paulo, n. 131, p. 175-195, abr. 2018. Disponível em: www.scielo.br/scielo.php?script=sci_arttext\&pid=S0101-66282018000100175\&lng=pt\&nrm=iso. Acesso em: 14 abr. 2019.

BRASIL. Lei no 4.829, de 5 de novembro de 1965. Institucionaliza o crédito rural. Diário Oficial da União. Brasília, 9 de novembro de 1965.

BRASIL. Il Plano Nacional de Desenvolvimento. Brasília: Presidência da República, set. 1974.

BRASIL. Lei no 7.802, de 11 de julho de 1989. Dispõe sobre a pesquisa, a experimentação, a produção, a embalagem e rotulagem, o transporte, o armazenamento, a comercialização, a propaganda comercial, a utilização, a importação, a exportação, o destino final dos resíduos e embalagens, o registro, a classificação, o controle, a inspeção e a fiscalização de agrotóxicos, seus componentes e afins, e dá outras providências. Diário Oficial, Brasília, 11 de julho de 1989.

BRASIL. Congresso Nacional. Projeto de Lei PL 6.299/2002. Altera os arts. 3o e 9o da Lei no 7.802, de 11 de julho de 1989 que dispõe sobre a pesquisa, a experimentação, a produção, a embalagem e rotulagem, o transporte, o armazenamento, a comercialização, a propaganda comercial, a utilização, a importação, a exportação, o destino final dos resíduos e embalagens, o registro, a classificação, o controle, a inspeção e a fiscalização de agrotóxicos, seus componentes e afins, e dá outras providências. Disponível em: www.camara.gov.br/proposicoesWeb/prop_mostrarintegra;jsessionid=4B0E56524B9E282DC4C9324ED488D715.proposicoesWebExterno1?codteor=1673099\&filename=Avulso+-PL+6299/2002 Acesso em: 14 abr. 2019.

BRASIL. Congresso Nacional. Parecer do Relator, Dep. Luiz Nishimori (PR-PR), pela constitucionalidade, juridicidade e técnica legislativa; pela adequação financeira e orçamentária; e, no mérito, pela aprovação do PL 6.299/2002 e dos PLs nos 2.495/2000, 3.125/2000, 5.852/2001, 5.884/2005, 6.189/2005, 1.567/2011, 1.779/2011, 4.166/2012, 3.200/2015, 3.649/2015, 6.042/2016 e 8.892/2017, apensados, com Substitutivo; e pela constitucionalidade, juridicidade e técnica legislativa; pela adequação financeira e orçamentária; e, no mérito, pela rejeição dos PLs nos 713/1999, 1.388/1999, 7.564/2006, 3.063/2011, 4.412/2012, 49/2015, 371/2015, 461/2015, 958/2015, 1.687/2015, 2.129/2015, 4.933/2016, 5.218/2016, 5.131/2016, 7.710/2017, 8.026/2017 e 9.271/2017, apensados. Brasília, 2018. Disponível em: www.camara.leg.br/proposicoesWeb/prop_mostrarintegra;jsessionid=E0635C6BA556B5DF9A8B6401B8739E84 . proposicoesWebExterno1 ?codteor=1669849\&filename=Parecer-PL629902-18-06-2018. Acesso em: 6 maio 2020.

BRASIL. Decreto no 5.630, de 22 de dezembro de 2005. Dispõe sobre a redução a zero das alíquotas da Contribuição para o PIS/PASEP e da COFINS incidentes na importação e na comercialização no mercado interno de adubos, fertilizantes, defensivos agropecuários e outros produtos, de que trata o art. 1ㅇ da Lei no 10.925, de 23 de julho de 2004. Diário Oficial, Brasília, 22 de dezembro de 2005 .

BRASIL. Decreto $n^{\circ}$ 591, de 6 de julho de 1992. Atos Internacionais. Pacto Internacional sobre Direitos Econômicos, Sociais e Culturais. Promulgação. Diário Oficial, Brasília, 07 de julho de 1992.

BRASIL. Decreto no 5.360, de 31 de janeiro de 2005. Promulga a Convenção sobre Procedimento de Consentimento Prévio Informado para o Comércio Internacional de Certas Substâncias Químicas e Agrotóxicos Perigosos, adotada em 10 de setembro de 1998, na cidade de Roterdã. Diário Oficial, Brasília, 31 de janeiro de 2005b.

BRASIL. Decreto no 5.472, de 20 de junho de 2005. Promulga o texto da Convenção de Estocolmo sobre Poluentes Orgânicos Persistentes, adotada, naquela cidade, em 22 de maio de 2001. Diário Oficial, Brasília, 20 de junho de 2005c.

BRASIL. Constituição Federal de 1988. Promulgada em 5 de outubro de 1988. Disponível em: www.planalto.gov.br/ccivil_03/ Constituicao/Constituicao.htm. Acesso em: 14 abr. 2019.

BRASIL. Supremo Tribunal Federal. Ação Direta de Inconstitucionalidade no 3335/DF. Relator: ministro Edson Fachin. Brasília, 29 de junho de 2016. Disponível em: portal.stf.jus.br/processos/detalhe.asp?incidente=5011612. Acesso em: 7 mar. 2019.

CARNEIRO, F. F. et al. (org). Dossiê ABRASCO: Um alerta sobre os impactos dos agrotóxicos na saúde. Rio de Janeiro; São Paulo: [s.n.], 2015. 628 p. Disponível em www.abrasco.org.br/dossieagrotoxicos/wp-content/uploads/2013/10/DossieAbrasco_2015_web.pdf. Acesso em: 10 mar. 2020. 
CARSON, R. L. Primavera silenciosa. Tradução Claudia Sant'Ana Martins. 1ạ edição digital. São Paulo: Gaia, 2013.

CONFERÊNCIA DAS NAÇÕES UNIDAS SOBRE MEIO AMBIENTE E DESENVOLVIMENTO. Declaração do Rio sobre Meio Ambiente e Desenvolvimento. 1992. Disponível em: cetesb.sp.gov.br/proclima/wp-content/uploads/sites/36/2013/12/declaracao_rio_ ma.pdf. Acesso em: 12 abr. 2020.

DECLARAÇÃO UNIVERSAL DOS DIREITOS HUMANOS. Assembleia Geral das Nações Unidas em Paris. 10 dez. 1948. Disponível em: www.ohchr.org/en/udhr/documents/udhr_translations/por.pdf. Acesso em: 14 abr. 2019.

DEFENSORIA PÚBLICA DA UNIÃO. Nota Técnica № 1- DPGU/SGAI DPGU/GTGSAN DPGU - Defensoria Pública Geral da União. ANÁLISE DO PROJETO DE LEI 6.299/2002 (origem no PLS no 526, de 1999). Brasília, 2018. Disponível em: contraosagrotoxicos. org/wp-content/uploads/2018/05/SEI-_-DPU-2393350-Nota-Te\%CC\%81cnica-__DPU-PL-6.299.pdf. Acesso em: 10 mar. 2020.

DUNCK, E. A. F. M. Agrotóxicos e a intervenção do capital na agricultura. Revista de Direito Agrário e Agroambiental. Minas Gerais, v. 1, n. 2, p. 221-237, 2015. Disponível em: indexlaw.org/index.php/rdaa/article/view/328. Acesso em: 9 março 2019.

FIOCRUZ. Fundação Oswaldo Cruz. Nota Técnica. Assunto: Análise do Projeto de Lei no 6.299/2002. Rio de Janeiro, 2018. Disponível em: portal.fiocruz.br/sites/portal.fiocruz.br/files/documentos/nota_tecnica_pl_agratoxicos.pdf. Acesso em: 21 maio 2019.

FOLGADO, C. A. R. Agrotóxicos e estado de exceção: a suspensão da legislação de agrotóxicos em atenção aos interesses do agronegócio. In: SOUZA, Murilo Mendonça Oliveira de; FOLGADO, Cleber Adriano Rodrigues (org.). Agrotóxicos: violações socioambientais e direitos humanos no Brasil. Anápolis: Editora Universidade Estadual de Goiás, 2016a. p. 255-283.

FOLGADO, C. A. R. Sistema Normativo de Agrotóxicos na Contemporaneidade. Revista Jurídica da Universidade Estadual de Feira de Santana, v. 1, n. 1, 2016b. Disponível em: periodicos.uefs.br/index.php/revistajuridica/article/view/1819. Acesso em: 22 maio 2019.

FRENTE PARLAMENTAR DA AGROPECUÁRIA (Brasil). Composição. [2019-2022]. Disponível em: https://www.camara.leg.br/internet/deputado/frenteDetalhe.asp?id=53910. Acesso em: 13 abr. 2019.

FRIEDRICH, K.; SOUZA, M. M. O. de; CARNEIRO, F. F. (org.). Dossiê ABRASCO ABA: contra o PL do Veneno e a favor da Política Nacional de Redução de Agrotóxicos - PNARA. 2018. 39 p. Disponível em: www.abrasco.org.br/site/wp-content/uploads/2018/08/DOSSIE_NOVO_26_JULHO_Final-compressed2.pdf. Acesso em: 14 abr. 2019.

FURTADO, C. Formação econômica do Brasil. 29. ed. São Paulo: Companhia Editora Nacional, 1999.

JESUS, A. S. S. de; OMMATI, J. E. M. Segurança alimentar e revolução verde: questionamentos atuais acerca da luta contra a fome no plano internacional. Revista do Direito Público, Londrina, v. 12, n. 3, p. 191-215, dez. 2017. Disponível em: www.uel. br/revistas/uel/index.php/direitopub/article/download/28121/22687. Acesso em: 13 abr. 2019.

KAGEYAMA, A. O novo padrão agrícola brasileiro: do complexo rural aos complexos agroindustriais. In: DELGADO, G. C.; GASQUES, J. G.; VERDE, X. M. V (org.). Agricultura e políticas públicas. Brasília: Ipea, 1996. p. 113-224.

LAZZARI, F. M.; SOUZA, A. S. Revolução Verde: impactos sobre os conhecimentos tradicionais. In: CONGRESSO INTERNACIONAL DE DIREITO E CONTEMPORANEIDADE: MÍDIAS E DIREITOS DA SOCIEDADE EM REDE, 4., 2017, Santa Maria. Anais [...]. Santa Maria: UFSM, 2017. p. 1-16. Disponível em: http://coral.ufsm.br/congressodireito/anais/2017/4-3.pdf. Acesso em: 7 mar. 2020.

LONDRES, F. Agrotóxicos no Brasil: um guia para ação em defesa da vida. Rio de Janeiro: 2011. Disponível em: br.boell.org/ sites/default/files/agrotoxicos-no-brasil-mobile.pdf. Acesso em: 10 mar. 2020.

MINISTÉRIO PÚBLICO FEDERAL. Nota Técnica 4a CCR n.o 1/2018. Nota Técnica sobre o Projeto de Lei № $6.299 / 2002$ (origem no PLS no 526, de 1999) (Apensados: PL no 713/1999, 1.388/1999, 2.495/2000, 3.125/2000, 5.852/2001, 5.884/2005, 6.189/2005, 7.564/2006, 1.567/2011, 1.779/2011, 3.063/2011, 4.166/2012, 4.412/2012, 49/2015, 371/2015, 461/2015, 958/2015, 1.687/2015, 3.200/2015, 3.649/2015, 4.933/2016, 5.218/2016, 5.131/2016, 6.042/2016, 7.710/2017, 8.026/2017, 8.892/2017). Brasília, 2018. Disponível em: www.mpf.mp.br/pgr/documentos/4ccr_notatecnica_pl-6-299-2002_agrotoxico. pdf. Acesso em: 10 mar. 2020.

ONU. Organização das Nações Unidas. Mandates of the Special Rapporteur on the issue of human rights obligations relating to the enjoyment of a safe, clean, healthy and sustainable environment. OL BRA 5/2018. 13 June 2018. Disponível em: www. ohchr.org/Documents/Issues/ToxicWastes/Communications/OL-BRA-5-2018.pdf. Acesso em: 14 abr. 2019.

ONU. Organização das Nações Unidas. Report of the special rapporteur on the right to food. Human Rights Council. Thirty-fourth session, 27 Feb.-24 Mar 2017. Disponível em: www.ohchr.org/en/hrbodies/hrc/regularsessions/session34/pages/ listreports.aspx. Acesso em: 14 abr. 2019.

PELAEZ, V.; TERRA, F. H. B.; SILVA, L. R. da. A regulamentação dos agrotóxicos no Brasil: entre o poder de mercado e a defesa da saúde e do meio ambiente. Revista de Economia, Editora UFPR, v. 36, n. 1, a. 34, p. 27-48, jan./abr. 2010. Disponível em: revistas.ufpr.br/economia/article/viewFile/20523/13714. Acesso em: 14 abr. 2019.

PERES, F.; MOREIRA, J. C.; DUBOIS, G. S. Agrotóxicos, saúde e ambiente: uma introdução ao tema. In: PERES, F.; MOREIRA, J. C. (org.). É veneno ou é remédio? Agrotóxicos, saúde e ambiente. Rio de Janeiro: Editora Fiocruz, 2003. p. 21-42. Disponível em: books.scielo.org/id/sg3mt/pdf/peres-9788575413173.pdf. Acesso em: 14 abr. 2019. 
PIGNATI, W. Agronegócio, agrotóxico e saúde. In: SOUZA, M. M. O. de; FOLGADO, C. A. R. (org.). Agrotóxico: violações socioambientais e direitos humanos no Brasil. Anápolis: Editora Universidade Estadual de Goiás, 2016. p. 17-46.

PORTO, M. F. de S. O trágico Pacote do Veneno: lições para a sociedade e a saúde coletiva. Caderno Saúde Pública, Rio de Janeiro, v. 34, n. 7, 2018. Disponível em: www.scielo.br/scielo.php?script=sci_arttext\&pid=S0102=311-2018000700302X\&lng=en\&nrmisso. Acesso em: 14 abr. 2019.

SANTOS, M.; GLASS, V. (org.). Altas do agronegócio: fatos e números sobre as corporações que controlam o que comemos. Rio de Janeiro: Fundação Heinrich Böll, 2018. 58 p. Disponível em: https://br.boell.org/sites/default/files/atlas_agro_final_06-09. pdf. Acesso em: 10 mar. 2020.

SIMIONATTO, I.; COSTA, C. R. Como os dominantes dominam: o caso da bancada ruralista. Temporalis, [S.I.], v. 12, n. 24, p. 215-237, nov. 2012. Disponível em: www.portaldepublicacoes.ufes.br/temporalis/article/view/3094/3285. Acesso em: 14 abr. 2019. 